\title{
Floor Level Activity as a Sign of Congruency and Containment in Perthes' Disease
}

\author{
Arvind Kumar Yadav ${ }^{\circledR 1}$, Watson Thomas ${ }^{\circledR 1}$, Sandeep Kumar Chaudhari ${ }^{\circledR 1}$, Souvik Paul ${ }^{\circledR 2}$ \\ ${ }^{1}$ Junior Resident (Academic), Department of Orthopaedics, All India Institute of Medical Sciences, Rishikesh, Uttarakhand, India, ${ }^{2}$ Senior Resident (Academic), \\ Department of Orthopaedics, All India Institute of Medical Sciences, Rishikesh, Uttarakhand, India.
}

\section{Abstract}

Background: This study aims to note the role of floor level activities like squatting and sitting cross-legged as the indicator of healing with good containment and congruency in Perthes' disease in children below eight years of age. The research hypothesis of the study is that the functional outcome of the affected hip joint in the form of spontaneous, free and full painless floor level activity in day to day life of the child is a better indicator of outcome irrespective of the radiographic changes in the hip joint. Subjects and Methods: A retrospective observational study was conducted in a tertiary care university hospital. The study included all the patients diagnosed with Perthes' disease whose last radiological assessment showed signs of healing. Patients above eight years and patients who had not started showing radiological healing were excluded. Parameters assessed were the presence of lurch, pain at the hip joint, limb length discrepancy, range of motion at the hip joint and ability to sit cross-legged and squat and epiphyseal extrusion index on radiographs. Results: Nineteen hips in 18 patients met criteria with a mean age of $7.1 \pm 1.5$ years at presentation with a minimum follow-up of $30(30-72)$ months. None of the patients had any residual lurch or tenderness at the hip joint at final follow up and all were able to sit cross-legged and squat symmetrically and comfortably with significant improvement of motion at the hip joint $(\mathrm{p}<0.05)$. No correlation was noted among the clinical and radiological features; except the internal rotation at healing with epiphyseal extrusion index at healing. Conclusion: Clinical function holds the key primarily in the course of treatment of Legg-Calve-Perthes' disease. Conservative management in the form of bracing, floor level activities, and hip flexion and abduction exercises lead to congruency and containment in Legg-Calve-Perthes' disease up to the age of eight years.

Keywords: Perthes, Conservative, LCPD, Hip Joint, Cross-Legged

Corresponding Author: Arvind Kumar Yadav, Junior Resident (Academic), Department of Orthopaedics, All India Institute of Medical Sciences, Rishikesh, Uttarakhand, India.

E-mail: akyadavmdb@gmail.com

Received: 25 October 2020

Revised: 07 December 2020

Accepted: 17 December 2020

Published: 30 December 2020

\section{Introduction}

Legg-Calve-Perthes' disease (LCPD) is the aseptic osteonecrosis of the upper femoral epiphysis. The average age of presentation is usually six to eight years. Age plays a crucial role in the prognosis of the disease. The other factors which affect the prognosis are the presence of lateral extrusion of the femoral epiphysis, height of lateral pillar at presentation, range of motion of the hip at presentation, and during the course of the disease and shape of the femoral head at skeletal maturity, ${ }^{[1]}$ The future degeneration of the hip joint can be prevented by maintaining the congruency and containment during the disease. The objective of treating LCPD is to restore the full and painless function of the hip joint. This will automatically prevent secondary degenerative arthritis of the hip joint from occurring due to residual problems such as restricted hip motion, leg length discrepancy, abductor insufficiency, an incongruity of the hip, aspherical femoral head, coxa Magna, and poor coverage of the femoral head. ${ }^{[2]}$ The earliest historical methods used for its treatment were in lines of tuberculosis of the hip which was managed by bed rest, traction and weight relieving calipers. Gradually many surgical interventions like pelvis or femoral osteotomies were also advocated by certain studies. There are studies that concluded that treatment does not affect the outcome of the disease. ${ }^{[3,4]}$ Natural history studies of the disease by Catterall et al. have found most patients do well irrespective of treatment taken or not. ${ }^{[5]}$ However, a small set of patients have a poor outcome because of delayed presentation or recurrent loss of hip function and pain. There is currently no unanimity regarding the best form of treatment. Both conservative and surgical treatments are based on the concept of restoring the containment and coverage of the extruded femoral physis 
under the acetabulum to restore the congruency of the healing joint. This concept focuses on the containment of the physis in the acetabulum so that lateral extrusion is prevented and simultaneously the necrotic bone is absorbed and living bone restored. This can be achieved either non-surgically or surgically. Surgical methods of containment are reserved for older children above eight years of age. Classically, bracing has been the method of non-surgical containment in the younger age group. Also, the continuation of floor-level activities like sitting cross-legged or squatting leads to the containment of the femoral head in the acetabulum. These floor level activities are a sign of congruency as well in the absence of which symmetrical cross-legged sitting or squatting cannot be achieved. The aim of this study is to note the role of floor level activities in the maintenance of containment and congruency in Perthes' disease in children below eight years of age. The research hypothesis of the study is that clinical outcome or function during and after the activity of disease if restored fully need not correlate with the radiographic changes of the hip joint.

\section{Subjects and Methods}

This was a retrospective observational study at a tertiary level teaching institution based in northern India. The study period was from September 2014 to September 2017. Ethical clearance from the institutional review board and consent from the parents of patients were obtained. Medical records along with sequential $\mathrm{x}$-rays of patients diagnosed with LCPD who were treated conservatively were assessed from the medical records section. All the patients whose last radiological assessment showed signs of healing with a minimum followup of 30 months were included in this study. Patients above eight years and who had not entered the healing phase were excluded. All patients were managed by a standard protocol. The diagnosis was made clinically and radiologically. Routine pelvis with both hips radiographs in anteroposterior and frogleg lateral views was done. All hips were classified according to the Waldenstrom system of classification. ${ }^{[6]}$ Magnetic resonance imaging (MRI) was done in doubtful cases to rule out tuberculosis of the hip since it is widespread and endemic in the area of study. Any possible bilateral disease was also ruled out by MRI. Patients with acute symptoms of stiffness and pain were initially managed with bed rest, traction, and analgesics. After the subsidence of the acute symptoms, an abduction brace at night was advised to keep both hips abducted to around 35 to 40 degrees. Passive flexion exercise by the child himself in the form of kneechest exercises and active, antigravity abduction exercises of the hip in side-lying positions were prescribed [Figure 1]. The child was allowed non-restricted ambulation without a brace during the day. Normal schooling was allowed with restrictions on sports activities. Floor level activities in form of cross-legged sitting and squatting were advised to be performed daily. Culturally, children who eat their food sitting on the floor were encouraged to continue doing the same. The goal was to obtain symmetric abduction and external rotation, thereby the congruency of the affected hip as compared to the opposite side. Radiographs were obtained 3-monthly. Bracing was continued until the healing phase was noted on radiographs. The only indication for surgical intervention for these cases was the presence of hinged abduction which was noted on radiographs or MRI. Clinical parameters assessed were the presence of lurch, pain at the hip joint, limb length discrepancy, range of motion at the hip joint and ability to sit cross-legged and squat. Radiographs were evaluated for the staging of disease along with epiphyseal extrusion index [Figure 2]. ${ }^{[7]}$ The minimum follow-up period was 30 months. A descriptive statistical analysis of the collected data was done. Continuous variables are presented as mean \pm SD and categorical variables are presented as absolute numbers and percentages. A paired t-test was used to compare the initial values and values at the healing of clinical and radiological parameters. Fisher's exact test was used for the evaluation of qualitative variables. Pearson correlation was used to correlate clinical function with the radiological parameter in the healing phase. Statistical analysis was done in SPSS 24.

\section{Results}

A total of 19 hips in 18 patients met our criteria of study with a mean age of 7.1 years at presentation (6 to 8 years, SD $1.56)$ and a minimum follow-up of 30 months. The majority of the patients were male $(\mathrm{n}=14)$. The left hip was involved in 11 patients and one had bilateral involvement. The mean duration of symptoms was nine months in this study. Initial radiographs of all the patients showed the necrotic phase of LCPD. The comparison of the clinical features at presentation and healing is presented [Table 1,2]. None of the patients had any residual lurch or tenderness at the hip joint at healing and all were able to sit cross-legged and squat comfortably. There was no significant limb length discrepancy leading to any gait abnormality at healing. The range of motion of the hip in all planes showed significant improvement. The clinical improvement was irrespective of the change in the mean of epiphyseal extrusion index from initial to healing phase was $25.6 \%$ to $30.7 \%$ with normal values being less than $20 \%$. No correlation was noted among the clinical and radiological features except between the internal rotation at healing with epiphyseal extrusion index at healing [Figure $3 \&$ Table 3].

\section{Discussion}

The goals of treatment of LCPD are the restoration of range of motion, relief of symptoms, and containment of femoral head along with congruency. It is a well-established fact the Perthes' is a self-limiting disease. A congruently growing 


\begin{tabular}{|c|c|c|c|}
\hline Parameters & At presentation & At healing & p-value \\
\hline Lurch & $\mathrm{n}=18$ & $\mathrm{n}=0$ & $<0.05 *$ \\
\hline Tenderness at hip or knee & $\mathrm{n}=14$ & $\mathrm{n}=0$ & $<0.05^{*}$ \\
\hline Average limb length discrepancy & $0.57 \mathrm{cms}$ & $0.15 \mathrm{cms}$ & $<0.05$ \\
\hline Hip flexion range ( $95 \%$ Confidence Level) & 70.2 degrees $(13.2)$ & 128.9 degrees $(4.8)$ & $<0.05$ \\
\hline Hip extension range ( $95 \%$ Confidence Level) & 2.89 degrees (3.9) & 10 degrees (1.6) & $<0.05$ \\
\hline Hip abduction range (95\% Confidence Level) & 20 degrees $(4.8)$ & 35.5 degrees (3.4) & $<0.05$ \\
\hline Hip adduction range ( $95 \%$ Confidence Level) & 23.1 degrees (3.2) & 24.7 degrees $(3.4)$ & $<0.05$ \\
\hline $\begin{array}{l}\text { Hip internal rotation range }(95 \% \text { Confidence } \\
\text { Level) }\end{array}$ & 8.4 degrees $(4)$ & 27.3 degrees $(2.4)$ & $<0.05$ \\
\hline $\begin{array}{l}\text { Hip external rotation range ( } 95 \% \text { Confidence } \\
\text { Level) }\end{array}$ & 15.7 degrees $(3.3)$ & 31.8 degrees $(2.2)$ & $<0.05$ \\
\hline Ability to squat & $\mathrm{n}=4$ & $\mathrm{n}=18$ & $<0.05^{*}$ \\
\hline Ability to sit cross legged & $\mathrm{n}=0$ & $\mathrm{n}=18$ & $<0.05^{*}$ \\
\hline $\begin{array}{l}\text { Epiphyseal extrusion index }(\text { Normal }<20 \%) \\
(95 \% \text { Confidence Level })\end{array}$ & $25.6(4.07)$ & $30.7(5.23)$ & 0.06 \\
\hline
\end{tabular}

*Fischer exact test

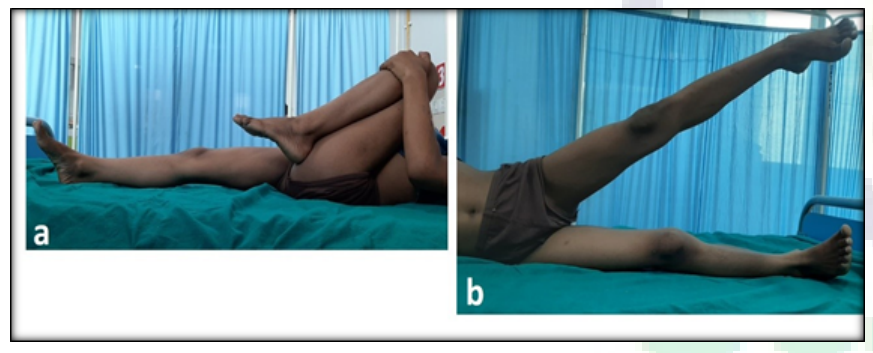

Figure 1: Passive flexion exercises.

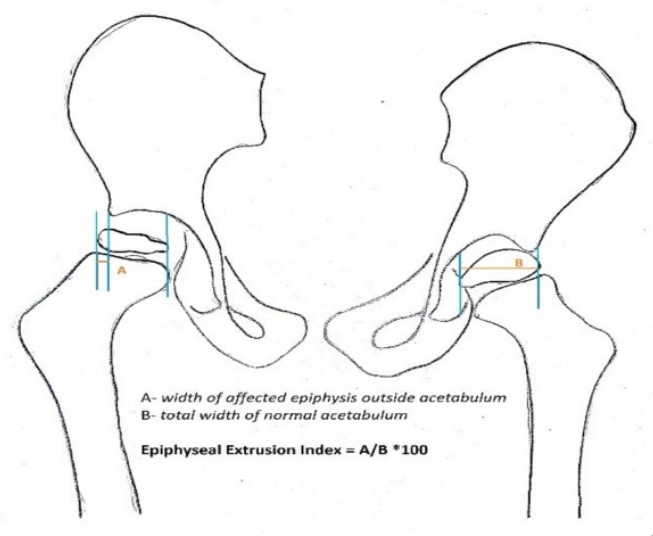

Figure 2: Epiphyseal Intrusion Index.

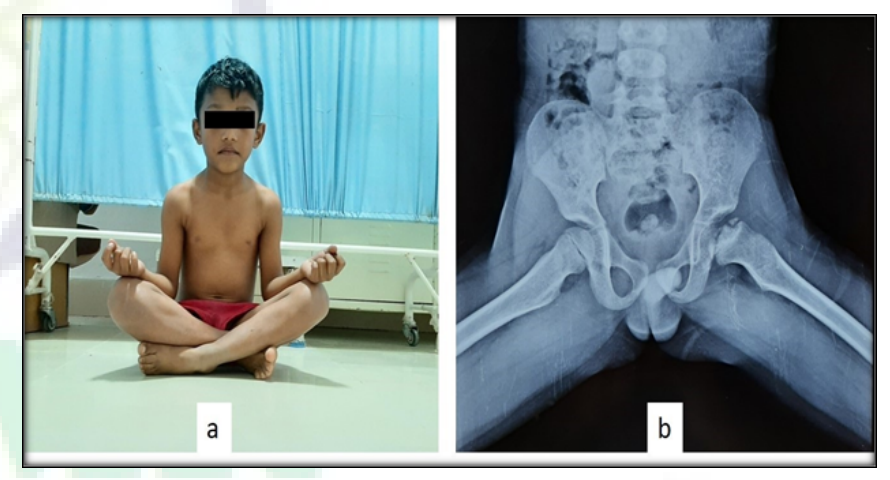

Figure 3: Correlation was noted among the clinical and radiological features at the internal rotation.

femoral head during and after the healing of the disease is the goal of treatment and is the best result of a healed Perthes' disease. The goal of containment is maintaining the sphericity and thereby the congruity of the femoral head which can be done in multiple ways. This is essential for the polyaxial movement of the hip joint. The normalcy of hip function is indicated by normal, symmetrical squatting on the floor which loads the hip joint normally. Many societies demand this function to be restored as an indicator of complete healing. Squatting provides a uniaxial movement of the normal hip while sitting cross-legged is an indicator of the full polyaxial movement of the hip joint. Nothing short of a normally contained and covered femoral head can achieve this. A normal hip has painless polyaxial movement, which 


\begin{tabular}{|c|c|c|c|c|c|c|c|c|c|c|c|c|c|c|c|c|c|}
\hline \multirow[t]{2}{*}{ Age } & \multirow[t]{2}{*}{ Sex } & \multirow[t]{2}{*}{ Side } & \multicolumn{3}{|l|}{ EEI (in \%) } & \multicolumn{2}{|c|}{ Flexion } & \multicolumn{2}{|c|}{ Extension } & \multicolumn{2}{|c|}{ Abduction } & \multicolumn{2}{|c|}{ Adduction } & \multicolumn{2}{|c|}{$\begin{array}{l}\text { Internal } \\
\text { Rotation }\end{array}$} & \multicolumn{2}{|l|}{$\begin{array}{l}\text { Exte } \\
\text { Rota } \\
\text { tion }\end{array}$} \\
\hline & & & Presentatio & & $\begin{array}{l}\text { Fina } \\
\text { fol- } \\
\text { low } \\
\text { up }\end{array}$ & Presı & $\begin{array}{l}\text { Fina } \\
\text { fol- } \\
\text { low } \\
\text { up }\end{array}$ & Presı & $\begin{array}{l}\text { Fina } \\
\text { fol- } \\
\text { low } \\
\text { up }\end{array}$ & Presı & $\begin{array}{l}\text { Fina } \\
\text { fol- } \\
\text { low } \\
\text { up }\end{array}$ & Presi & $\begin{array}{l}\text { Fina } \\
\text { fol- } \\
\text { low } \\
\text { up }\end{array}$ & Presı & $\begin{array}{l}\text { Fina } \\
\text { fol- } \\
\text { low } \\
\text { up }\end{array}$ & Pres & $\begin{array}{l}\text { Final fol- } \\
\text { low up }\end{array}$ \\
\hline 7 & M & L & 21.05 & & 29.16 & 35 & 80 & 0 & 0 & 20 & 35 & 10 & 30 & 0 & 20 & 10 & 20 \\
\hline 8 & M & $\mathrm{R}$ & 30 & & $13.6=$ & 45 & 100 & 0 & 10 & 25 & 35 & 10 & 35 & 10 & 25 & 20 & 40 \\
\hline 6 & M & $\mathrm{R}$ & 16 & & $19.0^{<}$ & 40 & 95 & 0 & 10 & 35 & 45 & 15 & 40 & 0 & 30 & 0 & 30 \\
\hline 8 & M & $\mathrm{L}$ & 22.22 & & $34.7 \varepsilon$ & 45 & 120 & 0 & 20 & 30 & 45 & 10 & 30 & 0 & 25 & 20 & 35 \\
\hline 6 & M & L & 22.22 & & 44 & 50 & 110 & 0 & 10 & 20 & 40 & 15 & 35 & 0 & 30 & 0 & 20 \\
\hline 7 & $\mathrm{~F}$ & $\mathrm{R}$ & 40 & & 21.0\{ & 55 & 100 & 10 & 20 & 25 & 40 & 15 & 30 & 0 & 20 & 0 & 25 \\
\hline 6 & M & $\mathrm{R}$ & 36.84 & & $40.9 x$ & 40 & 120 & 0 & 10 & 15 & 35 & 0 & 25 & 0 & 25 & 10 & 35 \\
\hline 7 & M & $\mathrm{R}$ & 26.92 & & 34.61 & 45 & 110 & 0 & 10 & 20 & 45 & 0 & 30 & 0 & 20 & 15 & 30 \\
\hline 7 & M & $\mathrm{L}$ & 27.27 & & $36.3 t$ & 60 & 115 & 10 & 20 & 30 & 50 & 15 & 35 & 10 & 40 & 20 & 50 \\
\hline 8 & M & $\mathrm{R}$ & 15 & & $36.8<$ & 50 & 110 & 0 & 15 & 20 & 40 & 10 & 30 & 10 & 45 & 20 & 50 \\
\hline 7 & M & $\mathrm{L}$ & 27.58 & & 21.42 & 45 & 100 & 0 & 10 & 15 & 45 & 0 & 30 & 0 & 40 & 0 & 45 \\
\hline 7 & $\mathrm{M}$ & $\mathrm{L}$ & 29.62 & & 31.81 & 65 & 110 & 10 & 20 & 25 & 40 & 10 & 35 & 0 & 30 & 10 & 30 \\
\hline 6 & $\mathrm{~F}$ & L & 22.72 & & 29.6 & 50 & 90 & 0 & 0 & 20 & 50 & 0 & 40 & 0 & 40 & 10 & 45 \\
\hline 6 & $\mathrm{~F}$ & $\mathrm{~L}$ & 15.78 & & 40 & 40 & 100 & 0 & 10 & 10 & 35 & 0 & 35 & 0 & 30 & 0 & 30 \\
\hline 8 & M & $\mathrm{L}$ & 31.57 & & $31.0=$ & 45 & 110 & 0 & 10 & 15 & 40 & 10 & 35 & 10 & 45 & 20 & 50 \\
\hline 8 & M & $\mathrm{L}$ & 36.84 & & 45 & 30 & 100 & 0 & 20 & 10 & 35 & 10 & 30 & 0 & 40 & 0 & 40 \\
\hline 8 & M & $\mathrm{R}$ & 15 & & $11.7 t$ & 55 & 120 & 10 & 15 & 20 & 50 & 15 & 40 & 0 & 35 & 10 & 45 \\
\hline \multirow[t]{2}{*}{8} & $\mathrm{~F}$ & $\mathrm{~B} / \mathrm{L}$ & $\mathrm{R}$ & 33.3: & 22.85 & 60 & 120 & 0 & 10 & 25 & 45 & 20 & 30 & 15 & 30 & 20 & 40 \\
\hline & & & $\mathrm{L}$ & 9.52 & $33.3=$ & 50 & 100 & 0 & 0 & 20 & 45 & 15 & 25 & 10 & 30 & 15 & 45 \\
\hline
\end{tabular}

EEI- Epiphyseal Extrusion Index ( $<20 \%$ - Good Prognosis, $>20 \%$ - Poor Prognosis) R- Right, L- Left.

\begin{tabular}{|lll}
\hline \multicolumn{1}{l}{ Table 3: Correlation of ROM of Hip at Healing Phase with Epiphyseal Extrusion Index at Healing Phase } \\
\hline Parameters & Correlation coefficient (r) & p-value \\
\hline Flexion & 0.1 & 0.6 \\
Extension & 0.04 & 0.9 \\
Abduction & 0.2 & 0.4 \\
Adduction & 0.2 & 0.5 \\
Internal rotation & 0.5 & $\mathbf{0 . 0 2}$ \\
External rotation & 0.3 & 0.3 \\
\hline
\end{tabular}

comes only by a congruent joint. The controversy in LCPD lies in its treatment. The majority of the modalities target the radiological changes as the indicator of treatment, which prompts surgical intervention to contain the deformed femoral head. As a consequence, a good-looking contained head-on xray is no guarantee of a fully mobile congruent, painless hip without limb length discrepancy. The principle of treatment has been postulated to relieve forces acting on the weak head to prevent its collapse and medialising the forces until the head reforms, which is obtained by containment. The efficacy of the treatment protocol does not concentrate on obtaining a fully functional hip joint but on a spherical head at the end of remodeling. Societies where the floor-level activity is not required in day-to-day life see no need to take it as the criteria of complete healing. No conventional non-surgical or surgical modality has been shown to alter the radiological course of 
the disease or its outcome. ${ }^{[8]}$ The research hypothesis of our study was based on clinical outcome or function during and after the activity of the disease. We did not correlate the outcome with the radiographic changes in the hip. There was no correlation between the epiphyseal extrusion index and the range of motion of the hip joint in this study, at last, follow up. The early painful hip was treated by symptomatic treatment i.e. analgesics, rest in bed with skin traction, or a spica cast for not more than 2 to 3 weeks. The rest of the treatment period was of full activity as much as the child could do, except restriction on jumping and running which increase the forces on a hip. The limp disappeared gradually as the child was encouraged to do passive hip flexion and antigravity abductor strengthening exercises. The polyaxial movements of the hip joint are needed in various floor activities like sitting cross-legged and squatting. Unlike the western population, floor-level activities are an integral part of activities of daily living in the Asian population. This posture needs an almost full range of hip flexion, abduction, and external rotation and can be used as a litmus test of hip function on an outdoor basis. Kinematic studies conducted on the Asian population have revealed that the range of motion of hip flexion and hip abduction reached $101.7^{\circ}$ and $43.2^{\circ}$ respectively in the cross-legged sitting posture. ${ }^{[9]}$ The spherical femoral head articulates with a different part of the acetabulum in different phases of the motion arc of the hip. Loss of sphericity of the femoral head in LCPD causes increased joint reaction forces and decreased range of motion of the hip. ${ }^{[9]}$ The ability of a child to sit cross-legged and squat may reflect the functional status and range of motion of the hip better than other methods. The inability to sit cross-legged or squat fully on the floor should be termed as 'hip at risk sign' rather than the radiological head at-risk signs. Also, it is difficult to assess the functional status of any joint in a child with the help of any questionnaire or functional scores. Assessment of the functional status was obtained by the ability of the child to sit cross-legged or squat on the floor painlessly in this study. Also known is the fact that primary hip osteoarthritis is rare in the Asian population and that the development of acetabulum and its remodeling has a genetic component, the effect of which needs to be studied in detail. ${ }^{[10]}$ These findings point towards the role of genetic as well as lifestyle factors that influence the outcome in Perthes' disease. Kendig et al. reported 26 hips each of LCPD treated with recumbency and Robert Jones abduction frame in one group and femoral varus osteotomy followed by a brace in the second group. ${ }^{[11]}$ In both groups, 14 hips (54\%) had good results. This study refuted the concept that femoral osteotomy promotes early healing and revascularization. They suggested that healing is mainly affected biomechanically than biologically. The findings of this study were seconded by Clancy et al. too. ${ }^{[12]}$ The softened femoral head needs to be maintained in the acetabulum and allowed to mold to a fitting shape during healing. Richards et al. reviewed 22 hips who were treated conservatively by adductor tenotomy and application of Petrie casts under general anaesthesia. ${ }^{[13]}$ They obtained spherical congruency of the hips in $95 \%$ at the end of follow-up. Fulford et al. compared two groups of patients treated by different methods. ${ }^{[14]}$ Forty-three hips were managed conservatively by ischial weight relieving calipers and 56 hips were treated by femoral varus osteotomy. They had similar results in both groups. Arthrogram had revealed deformed heads in both the groups thus suggesting that the surgical method of containment might not be superior to the conservative method. Kruse et al. reviewed the functional and radiological outcomes of LCPD patients in two groups, one managed by shelf acetabular procedure and the other group by non-operative means. ${ }^{[15]}$ There was a significant difference radiologically in terms of center edge angle and anteroposterior Mose sphericity but showed no significant difference clinically in terms of the range of motion and clinical score (Iowa hip score). The shelf procedure might improve the head coverage in the immediate postoperative period but its eventual effectiveness wasn't substantiated. These results might be attributed to the natural course of the disease as well as the biomechanical aspect of head containment.

The limitations of this study are its retrospective nature with a small number of cases with no control group. The follow-up is short of skeletal maturity, hence the outcome in terms of Stulberg criteria could not be ascertained. The same set of patients need to be followed up till skeletal maturity to complete this pilot study and obtain a final outcome. This study used the epiphyseal extrusion index as the radiological parameter for all children below eight years without classifying them according to the lateral pillar on radiographs. Numerous other parameters have been reported with varying importance which has not been assessed in this study.

The strength of this study is that it has shown the efficacy of floor-level activities like cross-legged sitting and squatting in maintaining containment and congruency of the femoral head in children below eight years of age. This study also finds out the correlation between the radiological outcome in terms of epiphyseal extrusion index and clinical outcome in terms of the range of motion in the hip joint in patients of LCPD treated conservatively. Further studies that are prospective as well as randomized with a longer follow-up and large sample size involving all age groups need to be planned to help in choosing the best strategy in the treatment of LCPD. Studies focused on the Asian continent population will shed more light on the racial predilection in LCPD. 


\section{Conclusion}

In conclusion, as envisaged by Catterall, the mode of containment does not influence the outcome of the disease and as noted from this study, the clinical outcome or function during and after the disease does not correlate with the radiological picture. Clinical function holds the key primarily in the course of treatment of LCPD. Patients up to the age of 8 years can be managed satisfactorily with conservative containment along with bracing, floor level activities, and flexion and abduction exercises of the hip, which help in the remodeling of the deformed femoral head. Genetic as well as lifestyle factors also add to the better remodeling of the hip joint.

\section{References}

1. Salter RB. Legg-Perthes disease: the scientific basis for the methods of treatment and their indications. Clin Orthop Relat Res. 1980;150:8-11.

2. Shah H. Perthes disease: evaluation and management. Orthop Clin North Am. 2014;45(1):87-97. Available from: https://doi. org/10.1016/j.ocl.2013.08.005.

3. Calvé J. Sur une forme particuliere de pseudo-coxalgie greffee sur des deformations caracteristiques de l'extremite superieure du femur. Rev Chir,. 1910;30:54-84.

4. Legg AT. The end results of coxa plana. J Bone Joint Surg. 1927;9(1):26-36.

5. Catterall A. The Natural History of Perthes' Disease. J Bone Joint Surg. 1971;53-B(1):37-53. Available from: https://dx. doi.org/10.1302/0301-620x.53b1.37.

6. Waldenstrom H. On coxa plana. Osteochondritis deformans coxae juvenilis. Leggs disease, maladie de Calvé, Perthes krankheit. Acta Chir Scand. 1923;55:577-59.

7. Green NE, Beauchamp RD, Griffin PP. Epiphyseal extrusion as a prognostic index in Legg-Calvé-Perthes disease. J Bone Jt Surg. 1981;63(6):900-905. Available from: https://dx.doi.org/ 10.2106/00004623-198163060-00006.

8. Weinstein SL. Natural History and Treatment Outcomes of Childhood Hip Disorders. Clin Orthop Relat Res . 1997;344:227-242. Available from: https://dx.doi.org/10. 1097/00003086-199711000-00023.
9. Salmingo RA, Skytte TL, Traberg MS, Mikkelsen LP, Henneberg KÅ, Wong C. A method to investigate the biomechanical alterations in Perthes' disease by hip joint contact modeling. Biomed Mater Eng. 2017;28(4):443-456. Available from: https://dx.doi.org/10.3233/bme-171685.

10. Froberg L, Christensen F, Pedersen NW, Overgaard S. The Need for Total Hip Arthroplasty in Perthes Disease: A Longterm Study. Clin Orthop Relat Res. 2011;469(4):1134-1140. Available from: https://dx.doi.org/10.1007/s11999-010-15663.

11. Kendig RJ, Evans GA. Biologic Osteotomy in Perthes Disease. J Pediatr Orthop. 1986;6(3):278-284. Available from: https: //dx.doi.org/10.1097/01241398-198605000-00004.

12. Clancy M, Steel HH. The effect of an incomplete interochanteric osteotomy on Legg-Calvé-Perthes disease. J Bone Jt Surg. 1985;67(2):213-216. Available from: https://dx.doi. org/10.2106/00004623-198567020-00006.

13. Richards BS, Coleman SS. Subluxation of the femoral head in coxa plana. J Bone Joint Surg Am. 1987;69(9):1312-1318.

14. Fulford GE, Lunn PG, Macnicol MF. A Prospective Study of Nonoperative and Operative Management for Perthes' Disease. J Pediatr Orthop. 1993;13(3):281-285. Available from: https: //dx.doi.org/10.1097/01241398-199305000-00001.

15. Kruse RW, Guille JT, Bowen JR. Shelf arthroplasty in patients who have Legg-Calvé-Perthes disease. A study of long-term results. J Bone Jt Surg. 1991;73(9):1338-1347. Available from: https://dx.doi.org/10.2106/00004623-199173090-00008.

Copyright: (C) the author(s), 2020. It is an open-access article distributed under the terms of the Creative Commons Attribution License (CC BY 4.0), which permits authors to retain ownership of the copyright for their content, and allow anyone to download, reuse, reprint, modify, distribute and/or copy the content as long as the original authors and source are cited.

How to cite this article: Yadav AK, Thomas W, Chaudhari SK, Paul S. Floor Level Activity as a Sign of Congruency and Containment in Perthes' Disease. Asian J. Med. Res. 2020;9(4): 5-10.

DOI: dx.doi.org/10.47009/ajmr.2020.9.4.OR2

Source of Support: Nil, Conflict of Interest: None declared. 